\title{
Chronic Tubal Ectopic Pregnancy containing a Complete Fetus inside: Case Report
}

\author{
Aherwar R ${ }^{1}$, Ahirwar $\mathbf{C P}^{2}$ \\ ${ }^{1}$ Dr. Rupa aherwar, senior Resident, Department of Obstetrics \& Gynecology, Gandhi Medical College, Bhopal, \\ ${ }^{2}$ Dr.chandraprakash ahirwar, Assistant Professor, Department of Radiodiagnosis, Gandhi Medical College, Bhopal, \\ India.
}

Address of correspondence: Dr. Rupa aherwar, E-mail: ahirwar.rupa@gmail.com

\begin{abstract}
A healthy 26 year old Para 1 presenting with a 2 months of amenorrhoea was diagnosed to have right tubal ectopic pregnancy after vaginal examination and ultrasonography. The case illustrates the need for careful history taking and considering ectopic pregnancy in women of reproductive age group even with negative pregnancy test. Emergency laparotomy confirmed swollen right tube containing a fetus with highly necrotic changes.
\end{abstract}

Key words: chronic ectopic pregnancy, Ultrasonography, human chorionic gonadotropin,

\section{Case Report}

A 26 year old patient, Para 1 with one living child presented with 2 months amenorrhea and off and on spotting per vaginum since 5 days and pain in the lower abdomen since 10 days. Urine pregnancy test was negative on the day of admission. She was married since last 3 years and had one male child of 2 years. Her past menstrual cycles were regular. There was no past history of any drug intake or previous surgery.

On general examination, she had tachycardia (Heart rate: 110 per minute), hypotension (blood pressure of 90/60 $\mathrm{mmHg}$ ) and pallor. Her abdomen was tender on palpation with positive rebound and guarding.

Abdominopelvic examination revealed tenderness in the lower abdomen. There was mild spotting; the cervical os was closed. Other findings on examination were tender transverse cervical movements, palpable tender right adnexal mass and fullness in all the fornices.

Ultrasound examination showed a complex right adnexal mass with non-homogeneous echo pattern, $8 \mathrm{~cm}$ size, with

Manuscript received: $06^{\text {th }}$ July 2013

Reviewed: $13^{\text {th }}$ July 2013

Author Corrected: $17^{\text {th }}$ July 2013

Accepted for Publication: 20 $0^{\text {th }}$ July 2013 an empty uterus. A moderate amount of fluid collection was present in the pouch of Douglas. Emergency exploratory laparotomy was performed. Haemoperitoneum of approximately $400 \mathrm{ml}$ was present. A 6-cm mass was noted in the ampullary portion of the right tube. The mass was filled with brownish fluid, containing a fetus with highly necrotic changes (Figure 1).

The crown-rump length of the fetus was about $2.0 \mathrm{~cm}$. In view of these findings, a right salpingectomy was done. The patient recovered uneventfully and was discharged on the 7 th post-operative day. Histopathology of the specimens confirmed the diagnosis of chronic right ectopic pregnancy.

\section{Discussion}

Although the incidence of ectopic pregnancy in the general population is about $2 \%$, the prevalence among pregnant patients presenting to an emergency department with firsttrimester bleeding or pain, or both, is $6 \%$ to $16 \% .{ }^{1-4}$ Thus, greater suspicion and a lower threshold for investigation are justified.

This is a case report of chronic ectopic pregnancy in

which the complete shape of the fetus was visible. Chronic ectopic pregnancy is a tubal gestation that has undergone 
abortion or repeated minor bleeding episodes, in which the hemodynamic insult is subclinical and self-limiting. ${ }^{5}$

The diagnosis can be easily missed in the absence of classical symptoms of ectopic pregnancy. Approximately $43-55 \%$ of ectopic pregnancies do not present with the classical triad of lower abdominal pain, period of amenorrhea and vaginal bleeding.., 7

Preoperative diagnosis is often difficult because of the high incidence of negative pregnancy tests as a result of a very small amount of live villi, subtle symptoms, and the poor specificity of ultrasonographic patterns. ${ }^{8}$ Because hCG levels cannot reliably eliminate the risk of tubal rapture in the case of chronic ectopic pregnancy, it should be considered in the differential diagnosis of patients with an adnexal mass even with low hCG levels and regular menses. ${ }^{9,10}$ The mass that occurs as the final form of chronic ectopic pregnancy is usually a conglomeration produced by adhesion between the inflamed tube after degeneration of the conceptus and surrounding structures, often containing blood and necrotic debris. ${ }^{11,12}$ In most cases, it occupies one adnexa and the cul-de-sac, yielding the heterogenous echo pattern. Some cases, around $10 \%$ of the cases Turan et al. examined, revealed a predominantly solid pattern. ${ }^{11}$. Another ultrasonographic finding that may help diagnosis is simple fluid collection in the pelvic cavity resulting from old blood, although a big difference in its incidence has been seen depending on the report.

In summary, the sonographic pattern of chronic ectopic pregnancy is very similar to that of pelvic inflammatory diseases and ovarian neoplasms without any specific feature. The differentiation of chronic ectopic pregnancy from other pelvic pathologies can only rely on a history of amenorrhea. Consequently, in almost all cases, diagnosis is possible only after pathological examination. In our case, however, the complex non-homogeneous adnexal mass consisted only of the conceptus and a thick capsule, accompanied by infiltration of blood cells, fibrin deposition, and fibrotic change. We speculate that, if the natural course had been observed, it would have resulted in findings identical to those of other cases reported previously. This case was intriguing because chronic ectopic pregnancy was detected at an early stage before absorption of the conceptus.

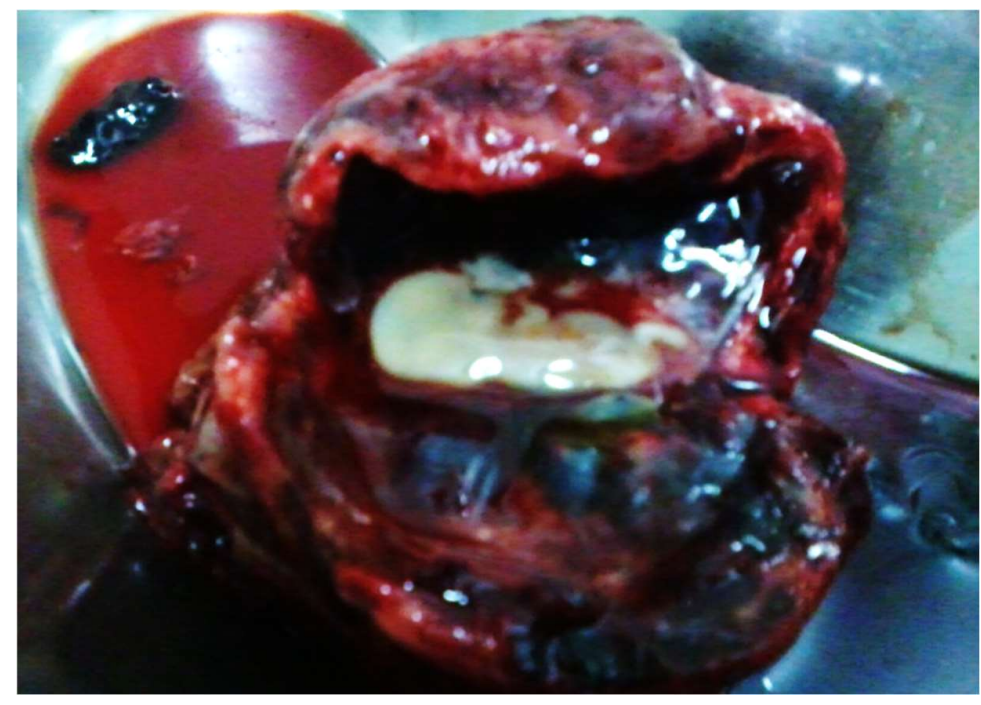

Figure 1: Excised chronic right tubal ectopic with drained out blood. Cut section revealed a fetus inside.

\section{References}

1. Barnhart K, Mennuti MT, Benjamin I, Jacobson S, Goodman D, Coutifaris C. Prompt diagnosis of ectopic pregnancy in an emergency department setting. Obstet Gynecol 1994; 84: 1010-5.

2. Dart RG, Kaplan B, Varaklis K. Predictive value of history and physical examination in patients with suspected ectopic pregnancy. Ann Emerg Med 1999; 33: 283-90.
3. Durham B, Lane B, Burbridge L, Balasubramaniam S. Pelvic ultrasound performed by emergency physicians for the detection of ectopic pregnancy in complicated first-trimester pregnancies. Ann Emerg Med 1997; 29: 338-47.

4. Sauer MV, Rodi IA. Utility of an algorithm to diagnose ectopic pregnancy. Int J Gynaecol Obstet 1990; 31: 29-34. 
5. Cole T, Corlett R. Chronic ectopic pregnancy. Obstet Gynecol 1982; 59: 63-68.

6. Dialani V, Levine D. Ectopic pregnancy: a review. Ultrasound Q. 2004 Sep;20(3):105-17.

7. Wong E, Suat SO. Ectopic pregnancy: a diagnostic challenge in the emergency department. Eur J Emerg Med. 2000 Sep;7(3):189-94.

8. Ugur M, Turan C, Vicdan K, Ekici E, Oguz O, Gokman O. Chronic ectopic pregnancy: A clinical analysis of 62 cases. Aust NZ J Obstet Gynecol 1996; 36: 186-189.

9. Brennan DF, Kwatra S, Kelly M, Dunn M. Chronic ectopic pregnancy - two cases of acute rupture despite negative beta hCG. J Emerg Med 2000; 19: 249-254.
10. Porpora MG, Alò PL, Cosmi EV. Unsuspected chronic ectopic pregnancy in a patient with chronic pelvic pain. Int J Gynaecol Obstet 1999; 64: 187-188.

11. Turan C, Ugur M, Dogan M, Ekici E, Vicdan K, Gokman O. Transvaginal sonographic findings of chronic ectopic pregnancy. Eur J Obstet Gynecol Reprod Biol 1996; 67: 115- 119.

12. Di Spiezio Sardo DI, Mastrogamvrakis A, Taylor G, Sharma M, Buck L, Magos A. Chronic ectopic pregnancy diagnosed incidentally in an infertile woman:A case report. J Reprod Med 2004; 49: 992 996

\section{How to cite this article?}

Aherwar R, Ahirwar CP Chronic Tubal Ectopic Pregnancy containing a Complete Fetus inside: Case Report. Int J Med Res Rev 2013;1(3):131-133. doi:10.17511/ijmrr.2013.i03.09 